\title{
A dish to die for
}

\section{Apes are still killed for their meat, but awareness of their plight is growing.}

\section{Eating Apes}

by Dale Petersen

University of California Press: 2003. 333 pp. $\$ 24.95, £ 16.95$

\section{Guy Cowlishaw}

The trade in wild meat is now perceived as one of the most important threats to global biodiversity. Nowhere is this more likely to be true than in tropical Africa, where the unsustainable hunting of wild animals has led to a 'bushmeat crisis' that threatens myriad forest species with extinction. Those most at risk are the great apes: gorillas, chimpanzees and bonobos (pygmy chimpanzees). Already living in small populations, the large body size of the apes makes them particularly attractive to hunters, while their slow reproductive rates make them unable to sustain even a modest offtake. Their biological characteristics are, quite literally, a recipe for disaster.

Despite early warnings in the 1970s and 1980s, the bushmeat trade only captured the attention of the wider international community in the mid-1990s. Part of the credit for this change in awareness is due to the photographer Karl Ammann, and his efforts to publicize the bushmeat trade through popular articles, television and an animalwelfare campaign. But it is Ammann's photographs that have been most influential. His dramatic images of butchered apes brought the bushmeat trade out of the African rainforest and presented it for scrutiny to the rest of the world.

Dale Petersen's Eating Apes, written with the assistance of Ammann (who also supplies the afterword), charts the history of Ammann's first exposure to the bushmeat trade and his role in bringing the trade to the attention of the Western public. As such, it is a fascinating account of some of the key people and events that have contributed to the development of one of today's most significant environmental movements. The underlying theme of Petersen's book, however, is not biographical or historical, but ethical: "Is it right, in the deepest moral sense, for one conscious being to eat another?"

The book begins with an exploration of the rich intellectual and emotional lives of our closest relatives. From this starting point, the narrative unfolds with a mixture of biography and science. Episodes in the life of Ammann and his associates are punctuated with numerous facts and figures about the bushmeat trade: accounts of how apes are hunted, the nutritional value of meat, the principles of sustainability, popular recipes for cooking gorilla, and perhaps most notably, the possi-

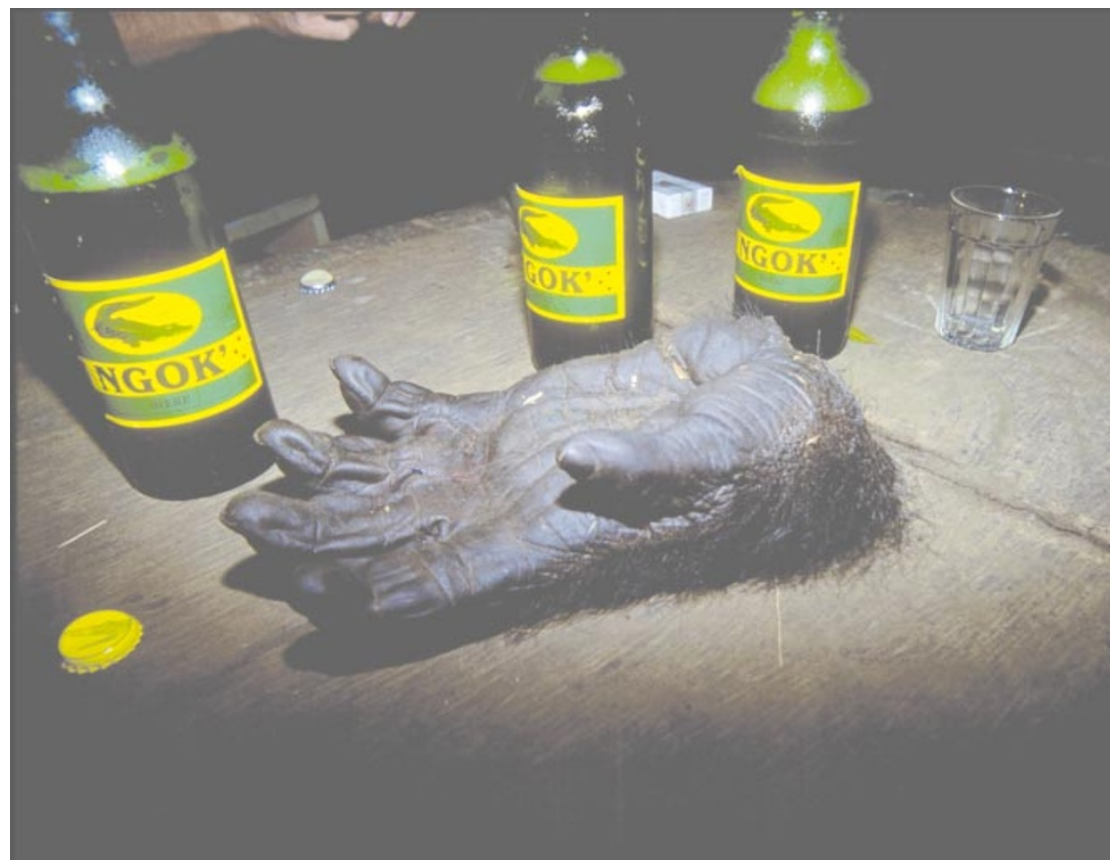

Hand to mouth: a gorilla hand in a Congolese restaurant throws the bushmeat trade into sharp relief.

bility that HIV/AIDS originated from simian immunodeficiency viruses that leapt from nonhuman primates to people through the hunting and handling of bushmeat.

The scale and complexity of the bushmeat crisis make it peculiarly difficult to identify a single underlying cause. Current thinking suggests a variety of factors, including human population growth, forest loss, greater accessibility to remote forest areas, the adoption of new hunting technologies (such as firearms and wire snares) and an increasing commercialization of the trade. Petersen focuses particular attention on logging operations, which can facilitate and promote the local bushmeat trade in all these ways. To tackle this problem, a number of conservation agencies have recently begun to work in collaboration with logging companies. These initiatives have met with mixed results. Through a detailed dissection of one such partnership, Petersen highlights his concerns about these schemes, namely transparency (a lack of independent assessment), equitability (a disproportional financialburden on the conservation partner) and exploitation (a public-relations victory for the logging industry). Petersen's conclusion is not that the collaborative approach should be abandoned, but rather that improved implementation is desirable. Indeed, one might imagine these difficulties as the inevitable growing pains of any new initiative to combat such a complex problem.
By following the progress of Ammann and his colleagues over the years, and by recounting both their victories and misadventures, Petersen provides a personal view of the bushmeat trade that is illuminating and eminently readable. The drawback of this approach is that it only represents one view of the current crisis. Petersen and Ammann are driven largely by concerns of welfare and the morality of hunting and eating apes. The conservation perspective, concerned with issues of wider biodiversity and ecosystem viability, is given considerably less coverage. The humanitarian perspective, concerned with the loss of income and food security to the bushmeat-dependent rural poor, is barely mentioned. Petersen's book should therefore not be considered as a definitive treatment of the bushmeat phenomenon.

Eating Apes is a strange stew - an emotive account of the bushmeat trade, and the threat it poses to the African apes, that is both popular and polemical. As such, it may not be to everybody's taste. Nevertheless, it is an absorbing mixture of biography, biology, anthropology, politics, economics and ethics. It is also thoroughly researched (extensive notes are provided for each chapter). Fittingly, it is illustrated by a selection of Ammann's most famous photographs. Guy Cowlishaw is at the Institute of Zoology, Zoological Society of London, Regents Park, London NW1 4RY, UK. 